\title{
ПСИХОЛОГИЧЕСКИЕ ПАРАМЕТРЫ СОЦИАЛЬНОЙ УСТАНОВКИ (АТТИТЮДА) В ОТНОШЕНИИ ВАКЦИНАЦИИ ОТ COVID-19
}

Ениколопов С.Н., Бойко О.М., Медведева Т.И., Воронцова О.Ю., Казьмина

О.Ю. (Федеральное Государственное Бюджетное Научное Учреждение «Научный чентр психического здоровья», Москва, Россия), enikolopov@mail.com

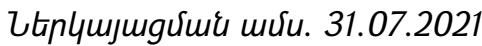

9pmpunuर्ume uर्रu. 10.08.2021

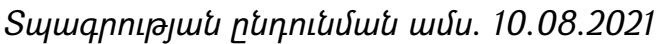

Целью исследования было изучение психологических переменных, связанных с социальными установками в отношении преодоления пандемии путём вакцинации. Материалами исследования стали данные интернет-опроса 1336 человек. Методы: использовались опросники SCL90-R, CTI, COPE, «Моральные дилеммы», аттитюд оценивался по вопросу «В чем Вы видите решение проблемы пандемии COVID-19». Полученные ответы в соответствии с активностью субъекта были условно разделены на два блока: «вакцинация»/«преодоление ситуации с помощью внешних обстоятельств». К первому типу был отнесён ответ «вакцинация», второй вариант включал в себя такие ответы как «само пройдёт», «найдут лекарство», «сформируется коллективный иммунитет». Результаты: аттитюд «вакцинация» более характерен для мужчин, связан представлением об опасности COVID-19 и со страхом за себя и других, с более тщательным соблюдением противоэпидемических правил, потребностью в творчестве, низкой паранояльностью, низким ощущением безнадёжности будущего, менее выраженными показателями категорического мышления (CTI). В области копинг стратегий данная социальная установка положительно коррелирует с планированием, концентрацией на эмоциях, с использованием инструментальной и эмоциональной социальной поддержки. Также отмечаются положительные связи с личностными выборами в методике «Моральные дилеммы».

Выводы: представления о вакцинации как о решении проблемы пандемии COVID-19 связаны с проактивной личностной социальной позицией и наличием психических ресурсов в области психического состояния, и в плане имеющихся стратегий совладания и переработки информации.

Ключевые слова: COVID-19, пандемия, аттитюд, копинг-стратегии, социальная установка, вакцинации.

DOI: https://doi.org/10.46991/SBMP/2021.4.2.150 
Индивидуальные представления о том, как разрешится ситуация пандемии COVID-19, составляют когнитивный компонент имеющейся социальной установки, аттитюда, который влияет на дальнейшее поведение человека. В отношении коронавирусной инфекции это показано в исследовании [8], продемонстрировавшем, что если человек воспринимает новую коронавирусную инфекцию как опасную болезнь, то он соблюдает больше противоэпидемических правил. Специалисты в области эпидемиологии и медицины считают, что прекращению пандемии может способствовать вакцинация [6], что подтверждается примером стран, где удалось вакцинировать большую часть населения, где на июнь 2021 года наблюдаются не только снижение показателей заболеваемости и смертности, но и стабилизация экономических показателей, общественной жизни при нулевой смертности от новой коронавирусной инфекции. Вакцинация от новой коронавирусной инфекции в настоящий момент является проявлением активного просоциального поведения, помогающего защитить не только себя, но и представителей уязвимых групп, а также предотвратить коллапс системы здравоохранения. Выжидательная стратегия может включать в себя ряд положительных аспектов для конкретного человека (возможность получить больше информации о действенности вакцинации, вероятность переболеть в лёгкой фрорме или избежать заболевания), однако приобретая широкую распространённость в обществе, она не даёт возможность контролировать иноекционный процесс.

С повышением доступности вакцинации выявилось наличие у людей разного отношения к ней, что демонстрирует важность психологических фракторов при принятии решения по поводу вакцинации. К настоящему моменту выявлены следующие фракторы, оказывающие влияние на готовность вакцинироваться: уже имеющийся опыт вакцинации, понимание действия вакцины и работы иммунитета, ею создаваемого, а также информация о клинических испытаниях и побочных действиях [8], уровень веры в конспиративные теории в отношении COVID-19 и вакцинации от него (происхождение, влияние на фертильность, чипирование и т.д.), пол, уровень образования (чем ниже - тем выше уровень) и наличие хронических заболеваний [10], возраст, уровень дохода и влияние на него пандемии [1], уровень доверия к работе медицинских служб во время пандемии, уровень доверия властям, [11] восприятие ковида как опасного заболевания, личное знакомство с людьми, болевшими ковидом, работа в области здравоохранения. Перечисленные данные в основном уделяют внимание социологическим переменным, исследований психологических особенностей личности, влияющих на то, в чем люди видят решение проблемы пандемии в настоящее время совсем мало. Так, одно из них выявило следующие психологические фракторы, коррелирующие с отрицательным отношением к вакцинации: завышенная самооценка, интернальный локус 
контроля, стремление доминировать [2], что является важным, но не достаточно, для понимания психологических факторов аттитюда в отношении вакцинации от COVID-19. Все это указывает на актуальность и значимость более глубокого изучения психологических характеристик когнитивного компонента социальной установки в отношении вакцинации от COVID-19.

Материалы и методы. Материал исследования был получен в ходе интернет-опроса с использованием google-forms с 31 марта 2020 года по 9.02.2021. Число респондентов, отличалось в разных методиках, т.к. респондент имел возможность на любом этапе завершить исследование.

Отношение к вакцинации исследовалось в ответе на вопрос «Откуда Вы ждете решения проблемы коронавируса?». Было предложено выбрать один из фриксированных ответов или написать свой. Ниже список предлагаемых ответов:

- Найдут лекарство

- Сделают вакцина

- Само пройдет

- Выработается коллективный иммунитет.

Для исследования психологических особенностей состояния респондентов, характера их реакций на сложные ситуации, а также особенностей саморегуляции использовались следующие методики:

- Общий блок вопросов, включавший демографические вопросы, а также вопросы, исследовавшие восприятие COVID-19, отношение и соблюдение противоэпидемиологических мер, а также направленные на общий скриннинг текущего психического состояния, был заполнен 1336 респондентами.

- Симптоматический опросник SCL-90-R (Simptom Check List-90-Revised) [5]. Опросник SCL-90-R включает в себя 90 утверждений, сгруппированных в ряд шкал, в том числе: депрессии, тревожности, враждебности, а также индекс тяжести состояния, индекс тяжести наличного дистресса и число беспокоящих пациента симптомов. Отдельно оценивалась выраженность таких симптомов, как «мысли о смерти», «мысли о суициде» и «ощущение, что будущее безнадежно». Был заполнен 967 респондентами.

- Опросник СОРЕ в адаптации Е.И.Рассказовой, Т.О.Гордеевой, Е.Н.Осина представляет собой русскоязычную версию опросника совладания со стрессом СОРЕ, авторами которого являются К.Карвер, М.Шейер и Дж.Вейнтрау. Он «предназначен для измерения как ситуационных копингстратегий, так и лежащих в их основе диспозиционных стилей» и состоит из 60 утверждений, составляющих 15 шкал [4]. Был заполнен 611 респондентами. 
- Constructive Thinking Inventory (Опросник категорического мышления «OKM97») Epstein 1987, в русскоязычной адаптации [3]. Был заполнен 475 респондентами.

- Тест «Моральные дилеммы», который представлял из себя выборку из 30 дилемм, предложенных Greene [7], переведённых на русский язык. Получены результаты 533 респондентов.

- Полученные данные обрабатывались в статпакете SPSS с применением коэфффициента корреляции Спирмена.

\section{Результаты}

Таблица 1. Результаты общей части опроса

\begin{tabular}{|l|l|}
\hline & Вакцина \\
\hline Возраст &,$- 131^{* *}$ \\
\hline Пол &,$- 068^{*}$ \\
\hline Не боюсь коронавируса &,$- 225^{* *}$ \\
\hline $\begin{array}{l}\text { Сумма используемых способов } \\
\text { противоэпидемической защиты }\end{array}$ &, $262^{* *}$ \\
\hline Потребность в творчестве &, $068^{*}$ \\
\hline $\begin{array}{l}\text { Представление об опасности } \\
\text { коронавируса }\end{array}$ &, $322^{*}$ \\
\hline
\end{tabular}

Примечания. Уровень статистической значимости: $\mathrm{p}<0.1 ;{ }^{*} \mathrm{p}<0.05$; ** $<<0.01$.

Социальная установка «вакцинация» в отношении новой коронавирусной инфекции отрицательно коррелирует с возрастом, отсутствием страха перед коронавирусом и женским полом, и положительно с увеличением количества используемых способов противоэпидемической защиты, представлением об опасности COVID-19, потребностью в творчестве.

C представлениями о вакцинации, как средстве преодоления пандемии, положительно коррелируют использование таких стратегий совладания как планирование, обращение за эмоциональной социальной поддержкой, обращение за инструментальной социальной поддержкой, концентрация на эмоциях, а также отрицательно коррелирует (на уровне статистической тенденции) такая стратегия переработки информации как категорическое мышление. Аттитюд «вакцинация» отрицательно коррелирует с общим уровнем паранояльности и со степенью согласия с утверждением «Ощущение, что будущее безнадёжно». Одновременно с этим социальная установка на вакцинацию положительно коррелирует с частотой личностных выборов в методике «моральные дилеммы». Отдельное внимание привлекают ответы на «медицинские» вопросы (в том числе 2 дилеммы про вакцины), присутствующие в этой методике. Наличие социальной установки на 
вакцинацию как способ преодоления новой коронавирусной инфекции всегда сопровождается личностными выборами в ответах на них.

Таблица 2. Результаты клинико-психологических методик

\begin{tabular}{|c|c|}
\hline параметр & Вакцина \\
\hline \multicolumn{2}{|l|}{ CTI } \\
\hline Категорическое мышление & $-0,078^{\sim}$ \\
\hline \multicolumn{2}{|l|}{ COPE } \\
\hline \multicolumn{2}{|l|}{ Мысленный уход } \\
\hline Концентрация на эмоциях &, $113^{* *}$ \\
\hline Использование инструментальной поддержки &, $104^{*}$ \\
\hline Использование эмоциональной социальной поддержки & $0,0783^{\sim}$ \\
\hline Планирование & ,099* \\
\hline \multicolumn{2}{|l|}{ SCL-90-R } \\
\hline Паранойяльность &,$- 071^{*}$ \\
\hline 54_Ощущение, что будущее безнадежно &,$- 072^{*}$ \\
\hline \multicolumn{2}{|l|}{ Моральные дилеммы } \\
\hline Личностные выборы & ,095* \\
\hline
\end{tabular}

Примечания. Уровень статистической значимости: $\mathrm{p}<0.1 ;{ }^{*} \mathrm{p}<0.05$; ${ }^{* *} \mathrm{p}<0.01$.

Обсуждение результатов. Статистическая обработка результатов позволяет проследить корреляции между социальной установкой на вакцинацию от COVID-19 и рядом психологических фракторов. Обращают на себя внимание данные, противоречащие результатам других исследований, а именно, что вакцинация как способ преодоления пандемии новой короновирусной инфекции коррелирует с более молодым возрастом. В совокупности с корреляциями с более высоким уровнем образования, это может объясняться спецификой нашей выборки, связанной с добровольностью участия респондентов в исследовании, воспринимаемом как возможность внести свой вклад в преодоление пандемии (именно об этом было написано в информационном тексте, сопровождавшем ссылку на опрос). Часть полученных нами данных подтверждают результаты коллег, например, положительные корреляции социальной установки на вакцинацию с восприятием COVID-19 как опасного заболевания [9], причём как для себя, так и с точки зрения потенциального причинения вреда другим. Последнее может быть связано с достаточно высокой субъективной значимостью других людей, об этом могут свидетельствовать положительные корреляции с такими стратегиями совладания как обращение за эмоциональной и инструментальной социальной поддержкой. При этом отрицательные корреляции с паранояльностью могут указывать на способность доверять и не искать подвох, что может играть важную роль в принятии решения о вакцинации, которое включают в себя 
готовность использовать недавно разработанную вакцину, возможное плохое самочувствие как реакцию организма на введение препарата, а также возможные отдалённые побочные последствия. Отрицательная корреляция аттитюда «вакцинация» с показателем «категорическое мышление» также объяснимы: она указывает на переносимость неидеальных решений, способность успокоить себя, примириться с имеющимися минусами, что в ситуации, когда заболевание совсем новое и вакцина от него разрабатывалась в сжатые сроки, обеспечивает психологические основания для принятия такого решения. Положительные корреляции социальной установки на вакцинацию с личностными выборами в методике «моральные дилеммы», в том числе с решением «медицинских дилемм» является в некотором роде закономерным. Дело в том, что само принятие решения о вакцинации является проявлением так называемого "личностного выбора" при котором человек не просто полагается на то, что ему повезёт и пассивно ждёт развития ситуации, но принимает на себя ответственность за возможные отрицательные последствия для него лично. Более того, само принятие решения о вакцинации или отсутствии вакцинации сходно по своей сути с решением моральных дилемм [6] - задач, не имеющих какого-то одного правильного решения, обсуждение которых приобрело дополнительную актуальность в связи с развитием искусственного интеллекта, и которые традиционно стоят, например, перед врачами. Так как пандемия вируса SARS-CoV-2 началась в конце 2019 года, то вакцины, разработанные для снижения вероятности заражения и тяжёлого, возможно, летального течения заболевания, а также прерывания вирусных цепочек, также разрабатывались срочно. При этом, несмотря на крайне низкую частоту серьёзных побочных действий, решение вопроса вакцинации от COVID-19 является дилеммой с выбором между альтруистическим поведением и вкладом в формирование коллективного иммунитета и эгоистическим, при котором выбирается надежда на то, что повезёт не заболеть и человек отказывается принимать решение о вакцинации [6]. Таким образом, важную роль в принятии вопроса о вакцинации может играть способность к самоутешению, преодолению страха перед вакциной. Последнее может объясняться такими способностями, с одной стороны, ощущать имеющиеся переживания - о чем говорят корреляции с таким типом копинг-стратегий как «концентрация на эмоциях», а с другой стороны, способностью сублимировать их в творчестве, на что указывают положительные корреляции с ощущаемой возросшей потребностью в творчестве. По всей видимости, свой вклад в обеспечение психологического базиса для социальной установки на вакцинацию вносит и меньшая неопределённость будущего, на что указывают отрицательные корреляции с утверждением «ощущение, что будущее безнадёжно». 
Таким образом, аттитюд «вакцинация как решение проблемы пандемии коронавирусной инфекции" является отражением проактивной личностной позиции, которая требует достаточно ресурсного состояния, как в области психического здоровья, так и в плане социальной интегрированности и внутреннего ощущения собственной вовлеченности в отношения с другими людьми, а также зрелости навыков и стратегий саморегуляции.

Выводы. Социальная установка в отношении вакцинации, как решении проблемы пандемии COVID-19 связана с проактивной личностной социальной позицией, эмоциональной вовлеченностью в отношения с другими людьми, и наличием психических ресурсов в области психического состояния, и в плане имеющихся стратегий совладания и переработки информации. Всё это, по всей видимости, создаёт условия, облегчающие личностной выбор, принятие решения, предполагающего субъективную ответственность за последствия и отказ от стратегии выжидания с надеждой на везение.

\section{Литература}

1. Бойко О.М., Медведева Т.И., Ениколопов С.Н., Воронцова О.Ю. Соблюдение противоэпидемических мер и интерпретации происходящего во время пандемии COVID-19. Девиантология. 2020; 4 (2): 8-21. DOI: 10.32878/devi.20-4-02(7), pp. 8-21.

2. Костина Л.А., Сергеева М.А., Кубекова А.С. Психологические свойства личности студентов, негативно относящихся К вакцинации от коронавируса (COVID-19) // Мир науки. Педагогика и психология, 2020 №5, https://mir-nauki.com/PDF/50PSMN520.pdf

3. Лебедев С.В., Ениколопов С.Н. Адаптация методик исследования посттравматических стрессовых расстройств. Психологическая диагностика, 2004, №. 3, pp. 19-38.

4. Рассказова Е.И., Гордеева Т.О., Осин Е.Н. Копинг-стратегии в структуре деятельности и саморегуляции: психометрические характеристики и возможности применения методики СОРЕ. Психология. Журнал высшей школы экономики, 2013, 10(1), pp. 82-118.

5. Тарабрина Н.В. Практикум по психологии посттравматического стресса. СПб.: Питер, 2001. 268 с.

6. Якутенко И. Цена прививки: почему обязательная вакцинация имеет смысл. Форбс. 11.06.2021 https://www.forbes.ru/obshchestvo/431895cena-privivki-pochemu-obyazatelnaya-vakcinaciya-imeet-smysl.

7. Greene J.D., Nystrom L.E., Engell A.D., Darley J.M., \& Cohen J.D. (2004). The neural bases of cognitive conflict and control in moral judgment. Neuron, 44(2), 389-400. doi:S0896627304006348 [pii]10.1016/j.neuron.2004.09.027. 
8. Perrotta D., Grow A., Rampazzo F. et al. Behaviours and attitudes in response to the COVID-19 pandemic: insights from a cross-national Facebook survey. EPJ Data Sci.10,17 (2021). https://doi.org/10.1140/epjds/s13688-021-00270-1.

9. Pogue K., Jensen J.L., Stancil C.K., Ferguson D., Hughes S. J., Mello E. J. , Burgess R. , Berges B. K. , Quaye A., Poole B. D. Influences on Attitudes Regarding Potential COVID-19 Vaccination in the United States Vaccines 2020, 8(4), 582; https://doi.org/10.3390/vaccines8040582.

10. Sallam M., Dababseh D., Eid H., Al-Mahzoum K., Al-Haidar A., Taim D., Yaseen A., Ababneh N.A., Bakri F.G., Mahafzah A. High Rates of COVID-19 Vaccine Hesitancy and Its Association with Conspiracy Beliefs: A Study in Jordan and Kuwait among Other Arab Countries Vaccines 2021, 9(1), 42; https://doi.org/10.3390/vaccines9010042.

11. Soares P., Rocha J.V., Moniz M., Gama A., Laires A.P., Pedro A.R., Dias S., Leite A., Nunes C. Factors Associated with COVID-19 Vaccine Hesitancy Vaccines 2021, 9(3), 300; https://doi.org/10.3390/vaccines9030300.

\section{PSYCHOLOGICAL VARIABLES OF ATTITUDE TOWARDS VACCINATION AGAINST COVID-19}

Enikolopov S.N., Boyko O.M., Medvedeva T.I., Vorontsova O.Yu., Kazmina O.Yu. (Federal Stare Budgetary Scientific Institution "Mental Health Research Center", Moscow, Russia)

Vaccination is an effective way to control the infection. Aim of the study was to investigate the psychological variables associated with attitude towards coping with the pandemic by vaccination. Materials: the data of an Internetsurvey of 1336 people. Methods: SCL-90-R, CTI, COPE, "Moral dilemmas" were used, the attitude was assessed according to the question. The responses received, in accordance with the activity of the subject, were divided into two blocks: "vaccination" / "overcoming the situation with the help of external circumstances." Results: "vaccination" attitude is more typical for men, associated with perception of danger of COVID-19, with more careful observance of anti-epidemic rules, the need for creativity, low paranoia, a low sense of hopelessness of the future, less indicators of categorycal thinking (CTI). In the field of coping strategies, this social attitude is positively correlated with planning, concentration on emotions, with the use of instrumental and emotional social support. There are also positive links with personal choices in "Moral 
Dilemmas".Conclusions: the attitude of vaccination as a solution to the COVID19 pandemic is associated with a proactive personal social position and the availability of mental resources.

Keywords: COVID-19, pandemics, attitude, coping strategies, social attitudes, vaccinations. 